\title{
Increased adipose tissue lipolysis in dairy cows with fatty liver is associated with enhanced autophagy activity
}

\author{
Jihong Dong, ${ }^{1}$ Kaiming Yue, ${ }^{1}$ Juan J. Loor, ${ }^{2} \oplus$ Ahmad Aboragah, ${ }^{2} \odot$ Guojin Li, ${ }^{1}$ Linfang Chen, ${ }^{1}$ Yuxiang Song,

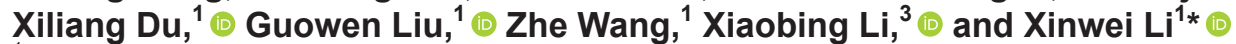 \\ ${ }^{1}$ Key Laboratory of Zoonosis Research, Ministry of Education, College of Veterinary Medicine, Jilin University, 5333 Xi'an Road, Changchun, \\ 130062, Jilin, China \\ ${ }^{2}$ Mammalian NutriPhysioGenomics, Department of Animal Sciences and Division of Nutritional Sciences, University of Illinois, Urbana 61801 \\ ${ }^{3}$ College of Veterinary Medicine, Yunnan Agricultural University, Kunming 650201, China
}

\section{ABSTRACT}

Lipolysis is increased in adipose tissue of cows with fatty liver during the transition period. Autophagy, a major cellular degradation process, plays a critical role in adipose tissue homeostasis. The objective of this study was to explore the relationship between lipolysis and autophagy in adipose tissue of cows with fatty liver. Using a nested case-control design, we compared blood and adipose tissue samples from 10 control cows [parity: median $=3$, range $=2-4$; days in milk: median $=8 \mathrm{~d}$, range $=5-10 \mathrm{~d}$; hepatic triacylglycerol content: median $=0.55 \%$ liver $\mathrm{wt}$, range $=0.48-0.61 \%$ liver $\mathrm{wt}]$ and 10 lactation stage-matched cows with fatty liver (parity: median $=3$, range $=2-4$; days in milk: median $=9 \mathrm{~d}$, range $=5-11 \mathrm{~d}$; hepatic triacylglycerol content: median $=6.28 \%$ liver wt, range $=2.86-7.75 \%$ liver wt). Data were analyzed using paired $t$-tests. Serum concentrations of free fatty acids and $\beta$-hydroxybutyrate were greater and glucose concentration was lower in cows with fatty liver, which we determined by using commercially-available kits. Furthermore, western blotting showed that increased protein abundance of ATGL (adipose triglyceride lipase), ATG5 (autophagyrelated gene 5), and ATG7; ratio of phosphorylated (p)-HSL (hormone-sensitive lipase) to HSL and MAP1LC3 (microtubule-associated protein 1 light chain 3, also called LC3-II) to LC3-I along with decreased abundance of PLIN1 (perilipin 1), SQSTM1 (sequestosome-1, also called p62), and the ratio of p-mTOR (phosphorylated mechanistic target of rapamycin) to mTOR in cows with fatty liver. Quantitative reversetranscription PCR revealed an increase in abundance of MAP1LC3 mRNA and a decrease in SQSTM1 mRNA in cows with fatty liver. These findings were

Received March 12, 2021.

Accepted October 24, 2021.

*Corresponding author: lixinwei100@126.com replicated using an adipocyte model. Primary cultures of calf adipocytes isolated from the adipose tissue of the peritoneal omentum and mesentery were treated with $10 \mathrm{~m} M$ 3-methyladenine (3-MA), $5 \mathrm{n} M$ rapamycin, $1 \mu M$ isoproterenol (ISO), and $1 \mu M$ ISO +10 $\mathrm{m} M$ 3-MA. Comparisons among groups were analyzed using one-way ANOVA. Compared with the control, the $1 \mu M$ ISO treatment upregulated the abundance of ATGL, the ratio of p-HSL to HSL and LC3-II to LC3I, and the glycerol content, whereas it downregulated the abundance of PLIN1 and p62 in calf adipocytes. Compared with the $1 \mu M$ ISO treatment group, $1 \mu M$ ISO $+10 \mathrm{~m} M$ 3-MA downregulated the abundance of ATGL, the ratio of p-HSL to HSL and LC3-II to LC3-I, and the glycerol content, whereas it upregulated the abundance of PLIN1 and p62. Compared with the control, the $5 \mathrm{n} M$ rapamycin treatment upregulated the abundance of ATGL, the ratio of p-HSL to HSL and LC3-II to LC3-I, and the glycerol content, whereas it downregulated the abundance of PLIN1 and p62 in calf adipocytes. Overall, these data indicated that increased lipolysis in adipose tissue of cows with fatty liver was associated with enhanced autophagy. However, the specific molecular mechanisms that link lipolysis and autophagy need to be further investigated.

Key words: dairy cow, fatty liver, adipose tissue, lipolysis, autophagy

\section{INTRODUCTION}

The incidence of fatty liver in high-yielding dairy cows during the postpartum period is particularly high and hampers productive efficiency (Reid, 1980; Wensing et al., 1997; Bobe et al., 2004). Hepatic triacylglycerol (TAG) content has been used previously to categorize cows as healthy $(<1 \%$ liver wt) or having mild $(1-5 \%$ liver wt), moderate ( $5-10 \%$ liver wt), or severe fatty liver ( $>10 \%$ liver wt; Bobe et al., 2004). Due to negative nutrient balance, an increase in lipolysis during 
the transition period causes fatty acids and glycerol release and leads to hepatic production of ketone bodies such as acetoacetate, BHB, and acetone (Liu et al., 2014; Du et al., 2017). Although hepatic adaptations to the influx of fatty acids are well-known (Loor, 2010), mechanisms regulating adipose tissue function during this time are not completely understood.

In nonruminants, the control of lipolysis is subject to complex interactions between perilipins and lipases (Wang et al., 2011). As reported in nonruminants, 95\% of TAG is hydrolyzed by ATGL (adipose triglyceride lipase) and HSL (hormone-sensitive lipase; Schweiger et al., 2006). The fact that cows with ketosis have greater abundance of phosphorylated (p)-HSL in adipose tissue suggested the existence of a similar mechanism (Xu et al., 2019a). As evidenced by greater in vitro abundance of ATGL and HSL in cow adipocytes, PLIN1 (perilipin 1) silencing was able to promote lipolysis (Zhang et al., 2018). Thus, targeting adipose tissue mechanisms to understand better the occurrence and development of fatty liver in dairy cows is important.

In nonruminants, autophagy (cytosolic degradation and recycling of cellular contents) is associated with adipocyte differentiation, adipose tissue development, and functional maintenance (Tao et al., 2019). In the process of cellular autophagy, there is intracellular membrane traffic toward the lysosome (Zhang et al., 2012). Two essential autophagy-related genes, ATG5 and $A T G 7$, are responsible for autophagosome formation (Jang et al., 2014). As an E1-like enzyme, ATG7 activates ATG12 and transfers it to ATG10 (Noda et al., 2013). The ATG5 conjugates ATG12, which then interacts with ATG16L and causes multimerization at the phagophore (Glick et al., 2010). Cytosolic microtubule-associated protein 1 light chain 3 (MAP1LC3, also called LC3)-I is conjugated to LC3-II and inserted into the extending phagophore membrane (Kabeya et al., 2000). The SQSTM1 (sequestosome-1, also called p62) protein that accumulates (in parallel with an inhibition of autophagy) interacts with LC3 through the LC3-interacting region and then is degraded by autophagy (Bjørkøy et al., 2005; Ichimura et al., 2008).

Cellular autophagy is responsive to signaling pathways such as mTOR (mechanistic target of rapamycin), which can restrain the initiation of autophagy via phosphorylating ULK1Ser757 (Kim et al., 2011). Increasing activity of mTORC1 inhibited ATGL abundance in epididymal fat of mice (Chakrabarti et al., 2013). Although our previous work has indicated that autophagy was an important biological mechanism in cows with fatty liver (Du et al., 2018; Chen et al., 2020), the potential role of autophagy in the lipolytic response during the peripartal period is unknown.
We hypothesized that increased lipolysis may be associated with enhanced autophagy activity in both bovine adipose tissue and adipocytes. Specific objectives were to identify the underlying associations between autophagy and lipolysis in adipocytes of dairy cows through the chemical activation or inhibition of autophagy along with the activation of lipolysis.

\section{MATERIALS AND METHODS}

\section{Experimental Design, Animals, and Diets}

The Jilin University Ethics Committee on the Use and Care of Animals approved all experimental procedures and handling of cows (Changchun, China; clinical trial SY202009014). According to previous experience, the abundance of LC3 in liver tissue and adipose tissue of ketosis cows was twice that of the control group, with a standard error of less than 0.5. Therefore, we calculated the mean of LC3 protein abundance in adipose tissue of control cows as 1 . We expected that the LC3 protein abundance of adipose tissue in cows with fatty liver would increase to a mean of 2 . Then, we performed a calculation using an online tool (https://www.bu.edu/researchsupport/ compliance/animal-care/working-with-animals/ research/sample-size-calculations-iacuc/, IACUC, 2018), specifically in terms of the appropriate standard deviation of $0.5(P=0.01,95 \%$ power $)$. To use the tool, users enter the estimated means and standard deviations for each group in the spreadsheet (Statistical_Explanation_Sample_Spreadsheet in the online tool), which does all the calculations automatically. We assumed that the standard deviation for cows with fatty liver was at least as large as that in the control cows. Upon these basic criteria, 9 cows per group were required. To avoid unforeseen issues that could lead to removal of cows, an extra animal was included in each group. Thus, 10 control cows and 10 cows with fatty liver were chosen for study. Using a nested casecontrol design, a total of 120 lactating Holstein cows from a dairy farm located in Heilongjiang province, China (number of parities: median $=3$, range $=2-5$; DIM: median $=7 \mathrm{~d}$, range $=3-13 \mathrm{~d}$ ), were selected to identify fatty liver.

All cows received routine physical examinations including changes in body temperature, pulse rate, respiratory rate, feed intake, and milk yield. Body weight of each cow was measured via weigh-bridge $1 \mathrm{~d}$ before the biopsy. According to previous reports, the BCS of each cow was assigned on the basis of a 1- to 5-point scale (Edmonson et al., 1989). Dry matter intake for each group $(\mathrm{kg} / \mathrm{d})$ was calculated as the difference between feed offered and feed refused every day for the 
last $3 \mathrm{~d}$ before biopsy. Milk production of each cow was recorded by an automatic milking system every day for the last $3 \mathrm{~d}$ before biopsy. Blood samples were taken with 5 -mL vacuum collection tubes (no anticoagulant, Sanli Medical Technology Development Co. Ltd.) on each of the last $3 \mathrm{~d}$ before biopsy via jugular venipuncture between 0630 and $0800 \mathrm{~h}$, centrifuged immediately at $1,500 \times g$ for $15 \mathrm{~min}$ at $4^{\circ} \mathrm{C}$, and serum stored at $-80^{\circ} \mathrm{C}$ until analysis.

Compared with the remaining 99 cows, 21 cows with reduced DMI and milk production, and elevated serum BHB concentrations (greater than $0.6 \mathrm{mM}$ ) were deemed at high risk of developing fatty liver. They were used for liver biopsy to measure TAG and classify them as healthy $(<1 \%$ TAG) or with mild-to-moderate fatty liver according diagnostic criteria proposed previously (Bobe et al., 2004). In preparation for biopsy, the skin of the 11th or 12th right intercostal space was shaved and sanitized with iodine scrub and $75 \%$ alcohol before a $2 \%$ lidocaine $\mathrm{HCl}$ (Sigma-Aldrich) injection was given subcutaneously to anesthetize the area. A 3-mm stab incision was then made using a sterile disposable scalpel blade. Tissue was obtained using a liver puncture needle (Shanghai Surgical Equipment Factory) inserted into the liver through the intercostal muscle layers. Tissue was immediately frozen in liquid nitrogen.

The TAG assay was performed with approximately $20 \mathrm{mg}$ of liver tissue homogenized in $400 \mu \mathrm{L}$ of lysis buffer. A portion of the resulting supernatant was used to detect total protein concentrations with the bicinchoninic acid method (P1511; Applygen Technologies Inc.). The remaining supernatant was used to measure TAG via enzymatic kit (E1013; Applygen Technologies Inc.) according to the manufacturer's instructions. We mixed $10 \mu \mathrm{L}$ of supernatant with $190 \mu \mathrm{L}$ of working reagent; then, the mixture was incubated at $37^{\circ} \mathrm{C}$ for 10 min, and absorbance values at $570 \mathrm{~nm}$ were measured using a spectrophotometer (Thermo Fisher Scientific). Each liver tissue sample was analyzed in triplicate. Last, 10 cows were diagnosed as having mild and moderate fatty liver. In addition, another 20 cows were selected randomly from the remaining 99 cows to measure TAG content. Thereinto, 19 cows were free from fatty liver (hepatic TAG content $<1 \%$ liver wt), and then 10 cows were randomly chosen as control cows.

Subcutaneous adipose tissues (approximately 3 $\mathrm{g} /$ cow) were collected via biopsy from 10 cows with fatty liver and 10 control cows according to previously published procedures (Zachut et al., 2017). In short, a $5 \times 5 \mathrm{~cm}$ area of skin at the tailhead was clipped, washed, and disinfected. Then, a 1.5- to $2.5-\mathrm{cm}$ stab incision through the skin and subcutaneous tissue was made. Tissue samples collected by blunt dissection were washed with saline, frozen immediately in liquid nitrogen, and stored at $-80^{\circ} \mathrm{C}$.

Cows received an intramuscular injection of penicillin $(12,000 \mathrm{IU} / \mathrm{kg}$ of BW) and streptomycin $(5 \mathrm{mg} / \mathrm{kg}$ of BW) after biopsy to prevent infection (Malafaia et al., 2017). In addition, after the liver and adipose tissue biopsies, cows with fatty liver received $1 \mathrm{~L}$ of glucose solution $(25 \%)$ by intravenous injections and $200 \mathrm{~mL}$ of propylene glycol, $15 \mathrm{mg}$ of niacin, and $80 \mathrm{mg}$ of choline orally daily for $5 \mathrm{~d}$ (Dong et al., 2020).

Subsequently, adipose tissue, liver, and blood samples of the 10 cows with fatty liver were compared with those of 10 lactation stage-matched control cows. A basic description of cows is provided in Table 1. All cows were milked at 0800 and $1530 \mathrm{~h}$, and fed at 0830 and $1600 \mathrm{~h}$ twice daily. Cows were housed in a tiestall barn and had free access to feed and water (Supplemental Table S1, http://doi.org/10.17632/nnh2gkg8nv .1; Dong, 2021).

Table 1. Baseline characteristics of control cows and cows with fatty liver ( $\mathrm{n}=10$ per group)

\begin{tabular}{|c|c|c|c|c|c|}
\hline \multirow[b]{2}{*}{ Item } & \multicolumn{2}{|c|}{ Control cows } & \multicolumn{2}{|c|}{ Cows with fatty liver } & \multirow[b]{2}{*}{$P$-value } \\
\hline & Median & $\mathrm{IQR}^{1}$ & Median & IQR & \\
\hline Parity & 3 & $2-4$ & 3 & $2-4$ & 0.73 \\
\hline DIM & 8 & $5-10$ & 9 & $5-11$ & 0.78 \\
\hline $\mathrm{BW}, \mathrm{kg}$ & 656 & $628-688$ & 670 & $637-697$ & 0.15 \\
\hline Milk, $\mathrm{kg} / \mathrm{d}$ & 31.8 & $29.3-33.1$ & 29.1 & $28.1-31.6$ & 0.04 \\
\hline DMI, $\mathrm{kg} / \mathrm{d}$ & 21.1 & $20.4-21.7$ & 19.6 & $18.2-20.7$ & 0.03 \\
\hline BCS & 3.15 & $2.97-3.18$ & 3.26 & $3.01-3.34$ & 0.07 \\
\hline Glucose, $\mathrm{m} M$ & 3.92 & $3.52-4.33$ & 3.19 & $2.61-3.49$ & 0.01 \\
\hline Fatty acids, $\mathrm{m} M$ & 0.29 & $0.18-0.42$ & 0.7 & $0.61-1.43$ & 0.002 \\
\hline $\mathrm{BHB}, \mathrm{m} M$ & 0.47 & $0.31-0.68$ & 1.31 & $0.84-2.04$ & 0.002 \\
\hline TAG, ${ }^{2} \%$ liver wt & 0.55 & $0.48-0.61$ & 6.28 & $2.86-7.75$ & 0.0002 \\
\hline
\end{tabular}




\section{Serum Analysis}

Commercially-available kits were used to measure serum concentrations of fatty acids, BHB, and glucose (fatty acids: FA115; BHB: RB1008; glucose: GL3815; Randox Laboratories) via a Hitachi 7170 autoanalyzer.

\section{Calf Primary Preadipocyte Isolation and Culture}

Adipocytes were isolated from 6 Holstein calves (age 1 $\mathrm{d}$, female, $30-40 \mathrm{~kg}$, healthy, fasting). After calves were anesthetized, adipose tissue from the peritoneal omentum and mesentery was obtained by surgical excision as previously described (Sun et al., 2019). For additional postoperative management, calves were injected with ampicillin (20 mg/kg i.m. twice daily) for $3 \mathrm{~d}$. Calves were monitored twice daily (i.e., incision inspection, behavior, appetite, urination, and defecation). Calves returned to the herd and received routine management once sutures were removed at 10 to $14 \mathrm{~d}$ of age.

To remove adherent blood, the tissue obtained was rinsed in sterile PBS containing penicillin $(2,500 \mathrm{U} /$ $\mathrm{mL})$ and streptomycin $(2,500 \mathrm{mg} / \mathrm{mL})$. The fascia and visible blood vessels were peeled away carefully and cut into pieces of approximately $1 \mathrm{~mm}$. Then, the resulting tissue was digested using $50 \mathrm{~mL}$ of Dulbecco's modified Eagle medium (DMEM)/F12 (SH30023.01; HyClone) digestion solution containing collagenase type I (1 mg/ $\mathrm{mL}$, Sigma-Aldrich) and incubated in a slow-shaking water bath at $37^{\circ} \mathrm{C}$ for $1.5 \mathrm{~h}$. We used $80-\mu \mathrm{m}$ and $40-$ $\mu \mathrm{m}$ cell sieves to sequentially filter the mixture before centrifugation at $175 \times g$ at room temperature for 10 min. The ACK lysis buffer (Beyotime Institute of Biotechnology) was added to the precipitate to remove residual erythrocytes and then centrifuged at $175 \times g$ at room temperature for $10 \mathrm{~min}$. The supernatant was discarded and the pellet was resuspended with basic culture medium (BCM; DMEM/F12 with 10\% fetal bovine serum and $1 \%$ penicillin/streptomycin). After cell counting, isolated adipocytes were transferred to a cell culture flask at $1 \times 10^{4} / \mathrm{cm}^{2}$ and incubated at $37^{\circ} \mathrm{C}$ and $5 \% \mathrm{CO}_{2}$ in a cell incubator. The BCM was replaced every $48 \mathrm{~h}$.

\section{Cell Treatments}

Adipocytes were differentiated following a published protocol (Sun et al., 2019). Primary cells were transferred to 6 -well plates and incubated at $37^{\circ} \mathrm{C}$ under $5 \% \mathrm{CO}_{2}$ in $\mathrm{BCM}$ until cell aggregation reached approximately $70 \%$. The BCM was then replaced with freshly-prepared differentiation culture medium
(DCM) 1 [BCM supplemented with $0.5 \mathrm{~m} M$ IBMX (I-7018 Sigma-Aldrich), $1 \mu M$ dexamethasone (D-4902 Sigma-Aldrich), and $1 \mu \mathrm{g} / \mathrm{mL}$ insulin (I-5500 SigmaAldrich)] to induce preadipocytes to differentiate into mature adipocytes. The DCM1 was replaced with DCM2 (BCM supplemented with $1 \mu \mathrm{g} / \mathrm{mL}$ insulin) after $48 \mathrm{~h}$. The DCM2 was replaced every $48 \mathrm{~h}$ until visible cellular lipid droplets (LD) appeared, indicating adipocytes completed differentiation. Approximately $10 \mathrm{~d}$ elapsed during this period.

Cells were treated when partly differentiated assessed via oil red O staining (Supplemental Figure S1, http: //doi.org/10.17632/nnh2gkg8nv.1, Dong, 2021; Park et al., 2010). Methods for adipocyte treatment were similar to a previous study (Xu et al., 2019b) with minor modifications. To ensure the same sampling time, mature adipocytes were assigned to the following treatments (Supplemental Figure S2, http://doi.org/ 10.17632/nnh2gkg8nv.1, Dong, 2021): (1) control: cells incubated with DMEM/F12 for 24 h; (2) cells incubated with DMEM/F12 for $20 \mathrm{~h}$ followed by treatment with 3-methyladenine (3-MA; 10 mM; S2767; Selleck Chemicals) for an additional $4 \mathrm{~h}$ (Wang et al., 2020); (3) cells incubated with DMEM/F12 containing rapamycin (Rapa; $5 \mathrm{nM}$; S1039; Selleck Chemicals) for $24 \mathrm{~h}$ (Zhang et al., 2020); (4) cells incubated with DMEM/ F12 for $21 \mathrm{~h}$ followed by treatment with isoproterenol (ISO; $1 \mu M$; I6504; MilliporeSigma) for an additional $3 \mathrm{~h}$ (Andres Contreras et al., 2020); (5) cells incubated with DMEM/F12 for $20 \mathrm{~h}$ followed by treatment with 3 -MA $(10 \mathrm{mM})$ for $4 \mathrm{~h}$ and ISO $(1 \mu \mathrm{M})$ for $3 \mathrm{~h}$.

\section{Western Blotting}

Protein abundance of ATGL, p-HSL, HSL, PLIN1, p-mTOR, mTOR, ATG5, ATG7, LC3, p62, and $\beta$-actin in adipose tissue and adipocytes were determined by semiquantitative western blotting. Adipose tissue was cut into pieces before protein extraction. Adipocytes were scraped off the 6 -well plate with a cell scraper, washed with ice-cold PBS, and centrifuged at $4^{\circ} \mathrm{C}$, $1,000 \times g$ for $5 \mathrm{~min}$. Then, proteins from adipose tissue and adipocytes were isolated using the radioimmunoprecipitation assay lysis buffer (P0013B, Beyotime Institute of Biotechnology) containing a protease and phosphatase inhibitor cocktail (P1046, Beyotime Institute of Biotechnology). The bicinchoninic acid method was used to determine total protein concentration. A total of $30 \mu \mathrm{g}$ of protein from each sample with $4 \times$ protein SDS-PAGE loading buffer was denatured at $95^{\circ} \mathrm{C}$ for $10 \mathrm{~min}$. Then, proteins were separated using SDS-PAGE and transferred to $0.45-\mu \mathrm{m}$ polyvinylidene 
difluoride membranes. Subsequently, membranes were blocked with 3\% BSA/Tris-buffered saline/Tween (TBST) buffer solution at room temperature for $4 \mathrm{~h}$. Membranes were then incubated in TBST containing antibodies ATGL (1:1,000; ab99532; Abcam), p-HSL (1:1,000; \#4139; Cell Signaling Technology Inc.), HSL (1:1,000; ab45422; Abcam), PLIN1 (1:1,000; ab126639; Abcam), p-mTOR (1:1,000; ab84400, Abcam), mTOR (1:1,000; ab2732, Abcam), ATG5 (1:500, NB110, Novus Biologicals), ATG7 (1:1,000, D12B11; Cell Signaling Technology Inc.), LC3 (1:1,000; ab48394; Abcam), p62 (1:2,000; ab101266; Abcam), and $\beta$-actin (1:2,000; ab8226; Abcam) antibodies at $4^{\circ} \mathrm{C}$ overnight. According to the manufacturer, the species cross-reactivity of ATGL, PLIN1, p-mTOR, ATG5, ATG7, LC3, p62, and $\beta$-actin antibodies are predicted to work with bovine samples. The sequence homology of the target sequence for HSL and mTOR was $85.6 \%$ and $99.6 \%$, respectively. After washing 3 times with TBST buffer solution, membranes were incubated in TBST containing horseradish peroxidase-conjugated secondary antibodies at room temperature for $45 \mathrm{~min}$ as follows: anti-rabbit secondary antibody (1:5,000, Boster) for ATGL, p-HSL, HSL, PLIN1, p-mTOR, mTOR, ATG5, ATG7, LC3, and p62; and anti-mouse secondary antibody $(1: 5,000$, Boster) for $\beta$-actin. An enhanced chemiluminescence solution (Dalian Meilun Biotechnology Co. Ltd.) was used to visualize the blots. A simple protein imager (ProteinSimple) was used to capture images. Protein gray intensity was performed using Image-Pro Plus 6.0 (Media Cybernetics) and normalized to $\beta$-actin. Furthermore, p-mTOR was normalized to mTOR, p-HSL was normalized to HSL, and we analyzed the ratio of LC3-II to LC3-I.

\section{Quantitative Reverse-Transcription PCR}

Total RNA from adipose tissue was isolated with the RNAiso Plus kit (TaKaRa Biotechnology Co. Ltd.). The UV activity ratio at 260:280 $\mathrm{nm}$ was used to evaluate the RNA quality on a K5500 Micro-Spectrophotometer (Beijing Kaiao Technology Development Ltd.). The 260:280 nm ratio of all samples was 1.8 to 2.0. According to the manufacturer's instructions, we measured RNA concentrations at $260 \mathrm{~nm}$ and synthesized cDNA using a reverse-transcription kit containing random hexamers and oligo deoxythymine primers (RR047A; TaKaRa Biotechnology Co. Ltd.). The SYBR green plus reagent kit (Roche) was used to conduct quantitative reverse-transcription PCR on a 7500 Real-Time PCR System (Applied Biosystems Inc.). The reaction conditions were performed as follows: $95^{\circ} \mathrm{C}$ for $3 \mathrm{~min}$, followed by 40 cycles of $95^{\circ} \mathrm{C}$ for $15 \mathrm{~s}, 60^{\circ} \mathrm{C}$ for $1 \mathrm{~min}$.
Each sample was run in triplicate. We chose $A C T B$ and $G A P D H$ as internal controls (Supplemental Figure S3, http://doi.org/10.17632/nnh2gkg8nv.1, Dong, 2021; Farke et al., 2008; Zhu et al., 2019). The mRNA abundance data were calculated with the $2^{-\Delta \Delta \mathrm{CT}}$ method. Primer design was performed using Primer Express software 5.0 (Applied Biosystems) using bovine reference sequences from NCBI. Primers were evaluated by BLAST search at NCBI (https://www.ncbi.nlm .nih.gov/gene/). The quality of primers was assessed via agarose gel electrophoresis using a Gel200 loading solution (Supplemental Figure S4, http://doi.org/10 .17632/nnh2gkg8nv.1, Dong, 2021; All-Purpose, Native Agarose; AM8556; Thermo Fisher Scientific). Primers for MAP1LC3, SQSTM1, ACTB, and GAPDH used for this study are shown in Supplemental Table S2 (http:/ /doi.org/10.17632/nnh2gkg8nv.1, Dong, 2021).

\section{Glycerol Content Determination}

The supernatant from adipocyte cultures was collected to determine glycerol content using a commercial kit (E1002, Applygen Technologies Inc.) according to the manufacturer's instructions. A total of $50 \mu \mathrm{L}$ of supernatant was mixed with $150 \mu \mathrm{L}$ of chromogenic liquid and incubated for $10 \mathrm{~min}$ at $37^{\circ} \mathrm{C}$. Absorbance values were measured at $570 \mathrm{~nm}$ using a spectrophotometer (Thermo Fisher Scientific). Each sample was analyzed in triplicate.

\section{Statistical Analysis}

All data were analyzed using the SPSS 19.0 software package (IBM Corp.) and tested for normality. In vivo data with a normal distribution were analyzed using a parametric statistical analysis with paired $t$-tests. In vitro sample size was 6 (6 calves). Each measurement was performed in triplicate. In vitro cultures were used to compare different treatments using a-priori contrasts as follows: effect of inhibited autophagy (control vs. 10 $\mathrm{m} M$ 3-MA), effect of activated autophagy (control vs. 5 n $M$ Rapa), effect of activated lipolysis (control vs. $1 \mu M$ ISO), and effect of inhibited autophagy during enhanced lipolysis $(1 \mu M$ ISO vs. $1 \mu M$ ISO $+10 \mathrm{~m} M$ 3-MA). Comparisons among groups were analyzed using a one-way ANOVA with subsequent Bonferroni correction if data met homogeneity of variance; otherwise, we used Tamhane's T2 to analyze data with heteroscedasticity. Graphs were performed using GraphPad Prism 5.0 (GraphPad Software Inc.). Results with $P<$ 0.05 were considered significant. Results are reported as median \pm interquartile range or means \pm standard error of the mean. 

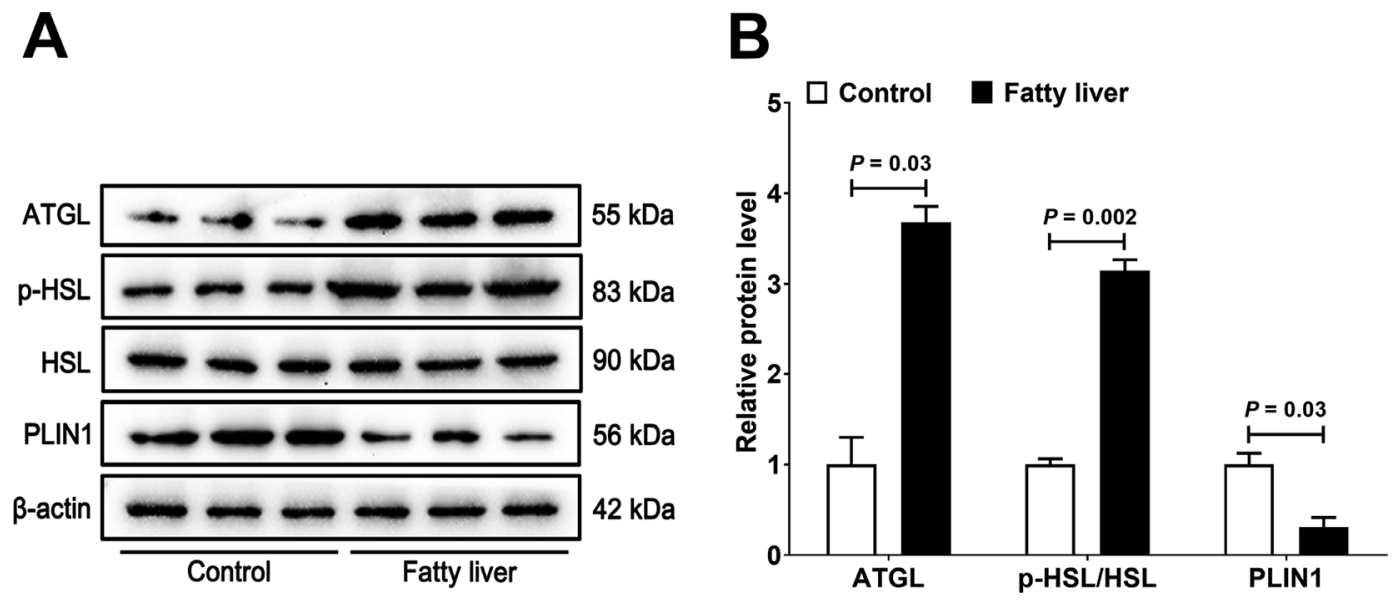

Figure 1. Effect of fatty liver in early lactating dairy cows on lipolysis profile. Panel A shows western blotting analysis of lipolysis as indicated by (panel B) the relative abundance of ATGL and PLIN1 and the ratio of phosphorylated (p)-HSL to HSL in adipose tissue of control cows and cows with fatty liver $(\mathrm{n}=10$ per group). Results are expressed as means \pm SEM. $P$-values indicate group differences.

\section{RESULTS}

\section{Baseline Characteristics and Serum Parameters}

Cows in the control and fatty liver group were of similar parity $(P=0.73)$, DIM $(P=0.78)$, BW $(P=0.15)$, and BCS $(P=0.07$; Table 1$)$. However, concentrations of fatty acids $(P=0.002)$ and $\operatorname{BHB}(P=0.002)$ were greater in cows with fatty liver (Table 1$)$. Milk production $(P=0.04)$, DMI $(P=0.03)$, and concentrations of glucose $(P=0.01)$ were lower in cows with fatty liver (Table 1). Liver TAG content was greater in cows with fatty liver $(P=0.0002$, Table 1$)$.

\section{Abundance of Lipolysis-Related Proteins in Adipose Tissue}

Protein abundance of ATGL $(P=0.03)$ and the ratio of p-HSL to HSL $(P=0.002)$ were greater in adipose tissue of dairy cows with fatty liver (Figure 1A and B). In contrast, protein abundance of PLIN1 was lower $(P$ $=0.03)$ in adipose tissue of dairy cows with fatty liver (Figure 1A and B).

\section{Abundance of Autophagosome Formation-Related Genes in Adipose Tissue}

The ratio of $\mathrm{p}$-mTOR to mTOR $(P=0.007)$ was lower in adipose tissue of dairy cows with fatty liver (Figure 2B and $\mathrm{C}$ ). Protein abundance of ATG5 ( $P$ $=0.03)$ and ATG7 $(P=0.03)$ were greater in adipose tissue of dairy cows with fatty liver (Figure $2 \mathrm{~B}$ and C). Adipose tissue MAP1LC3 mRNA abundance $(P=$ 0.0003; Figure 2A) and the ratio of LC3-II to LC3-I ( $P$ $=0.04$; Figure $2 \mathrm{~B}$ and $\mathrm{C}$ ) were greater in dairy cows with fatty liver, whereas the SQSTM1 mRNA $(P=$ 0.0002 ; Figure $2 \mathrm{~A})$ and p62 protein $(P=0.03$; Figure $2 \mathrm{~B}$ and $\mathrm{C}$ ) abundance was lower in cows with fatty liver.

\section{Effect of Autophagy Activity on Lipolysis in Calf Adipocytes}

Compared with the control, the ratio of LC3-II to LC3-I was lower $(P=0.0003$; Figure $3 \mathrm{~A}$ and B), whereas p62 protein abundance greater $(P=0.004$; Figure $3 \mathrm{~A}$ and $\mathrm{B}$ ) in adipocytes cultured with $10 \mathrm{~m} M 3$-MA. Addition of $5 \mathrm{n} M$ Rapa increased the ratio of LC3-II to LC3-I ( $P=0.0004$; Figure $3 \mathrm{~A}$ and B) and decreased the protein abundance of p62 $(P<0.0001$; Figure 3A and $\mathrm{B}$ ) compared with the control.

Compared with the control, addition of $10 \mathrm{mM} 3$-MA decreased the protein abundance of ATGL $(P=0.001$; Figure $3 \mathrm{C}$ and D), the ratio of p-HSL to HSL $(P<$ 0.0001 ; Figure $3 \mathrm{C}$ and $\mathrm{D})$, and the glycerol content $(P$ $=0.0004 ;$ Figure $3 \mathrm{E})$, whereas it increased the protein abundance of PLIN1 $(P=0.0002$; Figure $3 \mathrm{C}$ and D). However, compared with the control, addition of $5 \mathrm{n} M$ Rapa increased the protein abundance of ATGL $(P=$ 0.006; Figure 3C and D), the ratio of p-HSL to HSL $(P$ $=0.009 ;$ Figure $3 \mathrm{C}$ and $\mathrm{D})$, and the glycerol content $(P$ $=0.0005$; Figure $3 \mathrm{E})$, whereas it decreased the protein abundance of PLIN1 $(P<0.0001$; Figure $3 \mathrm{C}$ and D).

\section{Effect of Lipolysis on Autophagy in Calf Adipocytes}

Compared with the control, addition of $1 \mu M$ ISO increased the protein abundance of ATGL $(P=0.002$; Figure $4 \mathrm{~A}$ and $\mathrm{B})$, the ratio of p-HSL to HSL $(P=$ 0.0007; Figure 4A and B), and the glycerol content 
A

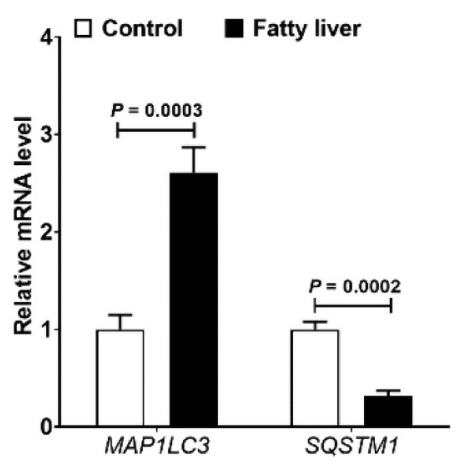

B

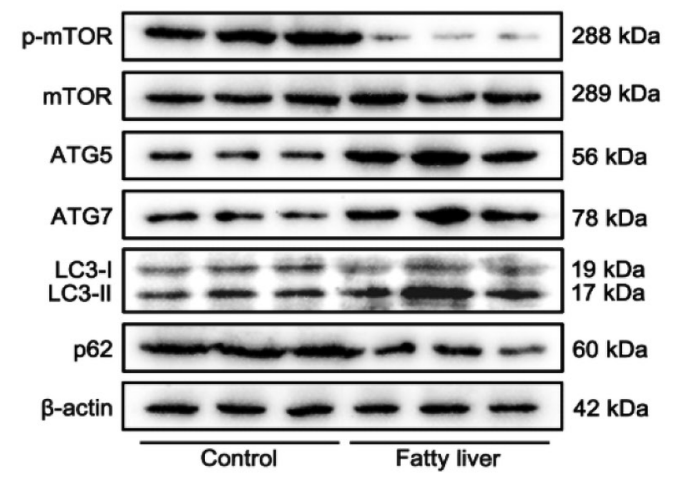

C

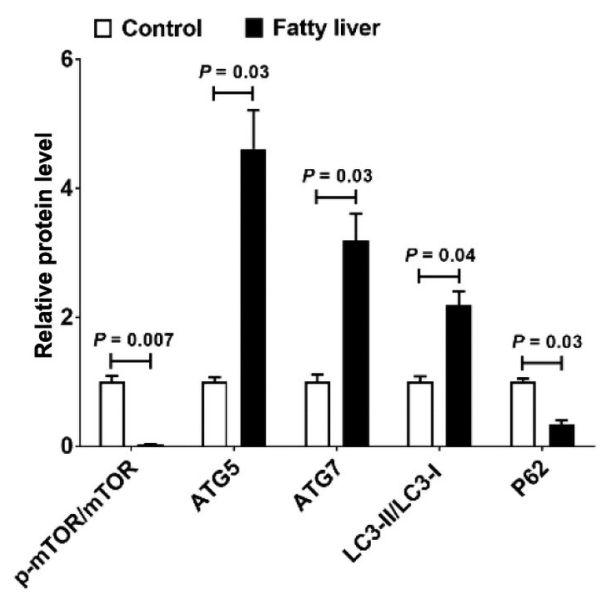

Figure 2. Effect of fatty liver in early lactating dairy cows on autophagy profile. Relative mRNA abundance of MAP1LC3 and SQSTM1 (panel A) and protein abundance of autophagy-related proteins (panel B) in adipose tissue of control cows and cows with fatty liver ( $\mathrm{n}=10$ per group). Autophagy-related proteins as indicated by the ratio of phosphorylated mechanistic target of rapamycin (p-mTOR) to mTOR, the relative abundance of ATG5, ATG7, and SQSTM1 (also called p62), and the ratio of MAP1LC3 (also called LC3-II) to LC3-I (panel C). Results are expressed as means \pm SEM. $P$-values indicate group differences.

$(P<0.0001 ;$ Figure $4 \mathrm{C})$, and decreased the protein abundance of PLIN1 $(P<0.0001 ;$ Figure $4 \mathrm{~A}$ and B). However, compared with $1 \mu M$ ISO treatment, addition of $1 \mu M$ ISO $+10 \mathrm{~m} M 3$-MA decreased the protein abundance of ATGL $(P=0.004$; Figure $4 \mathrm{~A}$ and $\mathrm{B})$, the ratio of p-HSL to HSL $(P=0.002$; Figure $4 \mathrm{~A}$ and $\mathrm{B})$, and the glycerol content $(P=0.008$; Figure $4 \mathrm{C})$, and it increased the protein abundance of PLIN1 $(P=0.005$; Figure $4 \mathrm{~A}$ and $\mathrm{B}$ ).

Compared with the control, the ratio of LC3-II to LC3-I was greater $(P=0.001$; Figure $4 \mathrm{D}$ and $\mathrm{E})$, whereas p62 protein abundance was lower $(P<0.0001$; Figure $4 \mathrm{D}$ and $\mathrm{E}$ ) in $1 \mu M$ ISO treatment groups. Compared with $1 \mu M$ ISO treatment, addition of $1 \mu M$ ISO $+10 \mathrm{~m} M$ 3-MA decreased the ratio of LC3-II to LC3-I $(P=0.01 ;$ Figure $4 \mathrm{D}$ and $\mathrm{E})$ and increased the protein abundance of p62 $(P=0.01$; Figure $4 \mathrm{D}$ and $\mathrm{E})$.

\section{DISCUSSION}

Negative nutrient balance acts as a trigger for fatty liver, which is caused by the massive nutrient demand for milk production exceeding the slow increase in DMI (Ospina et al., 2013; Jia et al., 2019; Klein et al., 2019). Although fatty acids arising from adipose lipolysis are readily used by liver as sources of energy, sustained increases in lipolysis not only increase TAG synthesis but also bring about lipotoxicity (Grummer, 1993; Jia et al., 2019). Misfolded proteins and damaged organelles are degraded after autophagosome fuse with lysosomes in a process termed autophagy (He and
Klionsky, 2009), which is activated when nutrient supply is limited (Singh et al., 2009; Cairó et al., 2016). Thus, autophagy helps maintain cellular homeostasis and cellular energy balance.

Our previous studies have shown that autophagy activity was enhanced in liver tissue of dairy cows with mild fatty liver (Chen et al., 2020) but impaired in cows with severe fatty liver (Du et al., 2018). Increased autophagy mediated the adaptive mechanism of the mammary gland in dairy cows with subclinical ketosis (Li et al., 2020). In this study, increased lipolysis during fatty liver was accompanied by enhanced autophagy in adipose tissue of dairy cows, as indicated by increased protein abundance of ATG5 and ATG7, the ratio of LC3-II to LC3-I, and decreased protein abundance of p62 and the ratio of $\mathrm{p}$-mTOR to mTOR. Thus, data illustrated that lipid metabolism in adipose tissue of dairy cows with fatty liver is associated with autophagy.

Under basal and activated lipolytic conditions, ATGL binds to LD and hydrolyzes TAG to diacylglycerol (Bolsoni-Lopes and Alonso-Vale, 2015; Kaushik and Cuervo, 2015). The protein PLIN, regarded as a "shield" at the LD surface, is highly expressed in white adipocytes and regulates the lipase's approachability to TAG (Kaushik and Cuervo, 2015; Zhang et al., 2018). During fasting or when there is an increase in energy demand, protein kinase A and G promote the phosphorylation of HSL and PLIN, leading to conversion of diacylglycerol to monoacylglycerol, which is subsequently hydrolyzed to glycerol by monoacylglycerol lipase (Bolsoni-Lopes and Alonso-Vale, 2015). In the present study, we found that 
abundance of PLIN1 was lower, whereas abundance of ATGL and the ratio of p-HSL to HSL were higher in adipose tissue of cows with fatty liver. This illustrated that the process of lipolysis was overactivated in adipose tissue of cows with fatty liver.

Pharmacological ISO treatment of 3T3-L1 cells and adipose tissue in mice stimulated lipolysis and release of fatty acids (Chitraju et al., 2017). A similar effect was detected in adipose tissue of periparturient dairy cows where incubation with ISO induced the activity of HSL and increased release of linoleic acid (Andres Contreras et al., 2020). This effect was confirmed in the present study through the increased abundance of ATGL, the ratio of p-HSL to HSL, and the glycerol content along with decreased abundance of PLIN1 in calf adipocytes. The increase in autophagic activity in response to ISO evidenced by the increased ratio of LC3-II to LC3-I, and decreased abundance of p62 suggested that autophagy activity was upregulated when adipocyte lipolysis was artificially enhanced. Thus, in vitro data confirmed and highlighted an association between increased lipolysis caused by pharmacological treatment with ISO and activation of autophagy. It should be noted that in the present study adipocytes were isolated from Holstein calves instead of peripartal cows to avoid the higher differentiation that characterize those cells (Björntorp et al., 1980; Ailhaud, 1982). Although pre-ruminant adipocytes do not reflect the in vivo condition in a dairy cow, they do represent a viable tool that can be used for mechanistic studies (i.e., work can be performed without the confounding effect of differences in feed intake, level of milk yield, and nutrient
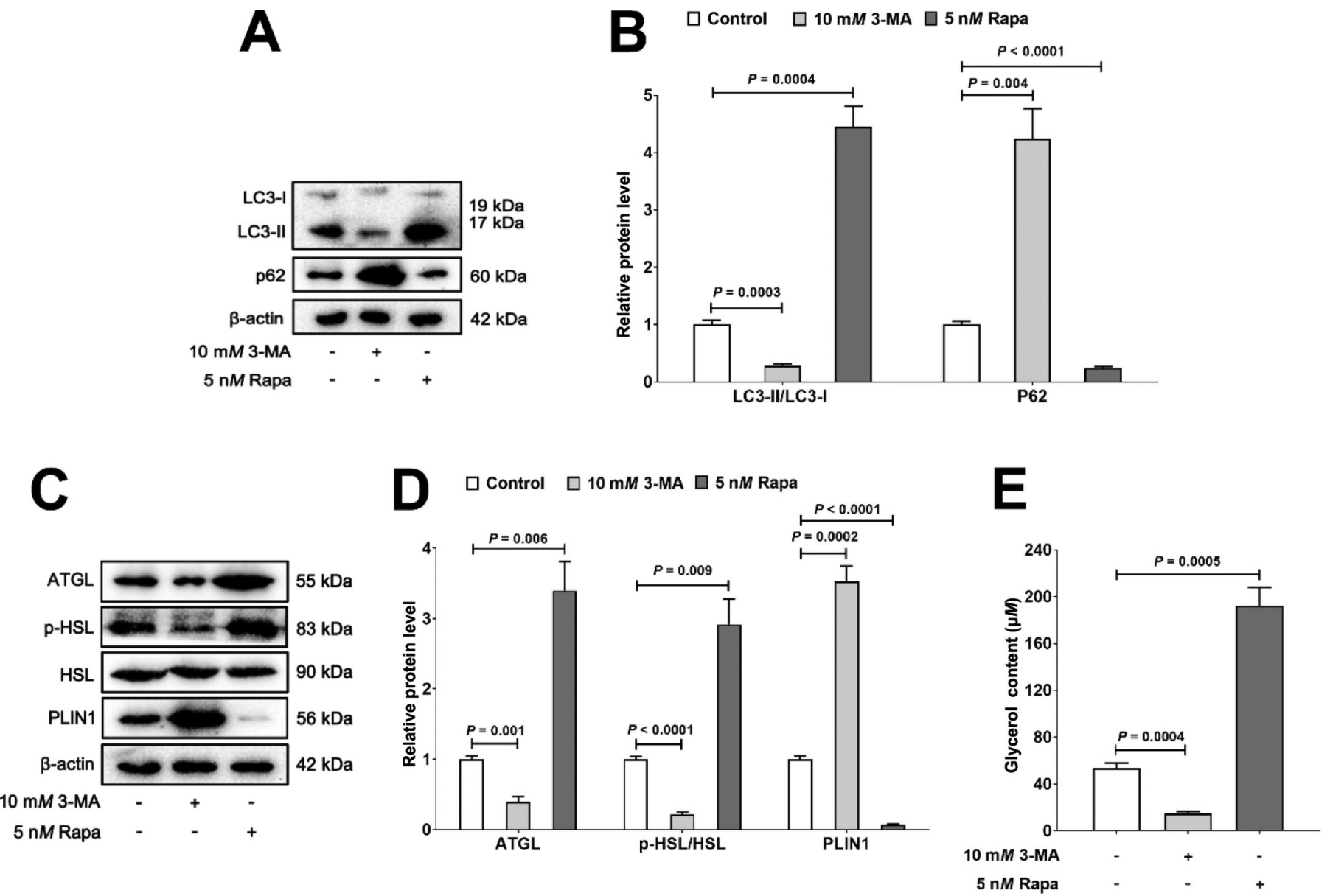

Figure 3. Effect of changed autophagy activity on lipolysis in calf adipocytes. Panel A shows representative western blotting analysis of autophagy-related proteins as indicated by the ratio of MAP1LC3 (also called LC3-II) to LC3-I and the relative abundance of SQSTM1 (also called p62; panel B). Panel C shows representative western blotting analysis of lipolysis-related proteins as indicated by the relative abundance of ATGL and PLIN1 and the ratio of phosphorylated (p)-HSL to HSL (panel D). Panel E shows glycerol content in the supernatant of cultured adipocytes. Calf adipocytes were assigned to 3 treatments as follows: (1) control: cells incubated with Dulbecco's modified Eagle medium (DMEM)/ F12 for $24 \mathrm{~h}$; (2) cells incubated with DMEM/F12 for $20 \mathrm{~h}$ followed by treatment with 3-methyladenine (3-MA; $10 \mathrm{mM}$ ) for an additional 4 h; (3) cells incubated with DMEM/F12 containing rapamycin (Rapa; $5 \mathrm{nM}$ ) for $24 \mathrm{~h}$. Results are expressed as means \pm SEM. $P$-values indicate group differences. Cell culture treatment was repeated using 6 calves, respectively. 
A B

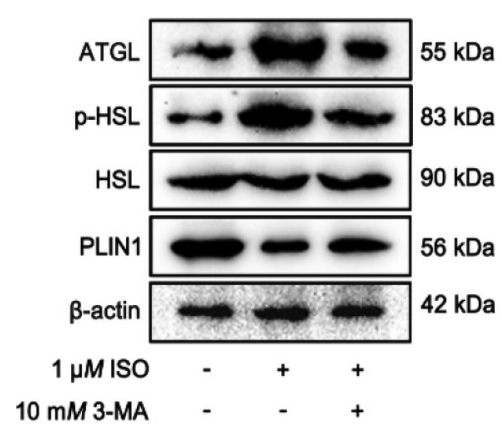

$\square$ Control $\quad \square 1 \mu M$ ISO $\quad \square 1 \mu M$ ISO $+10 \mathrm{mM}$ 3-MA

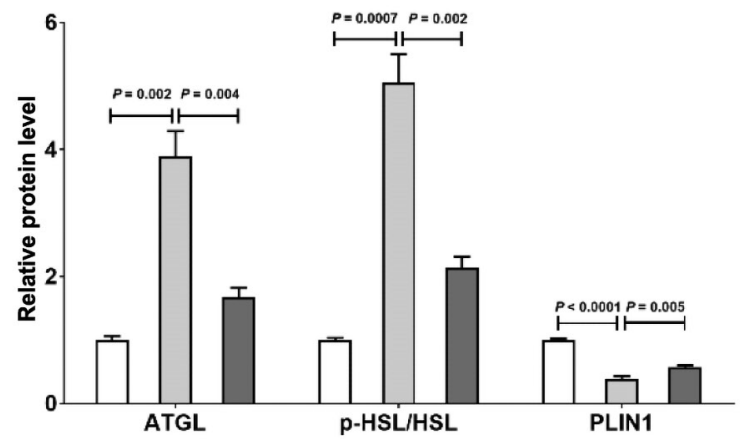

C

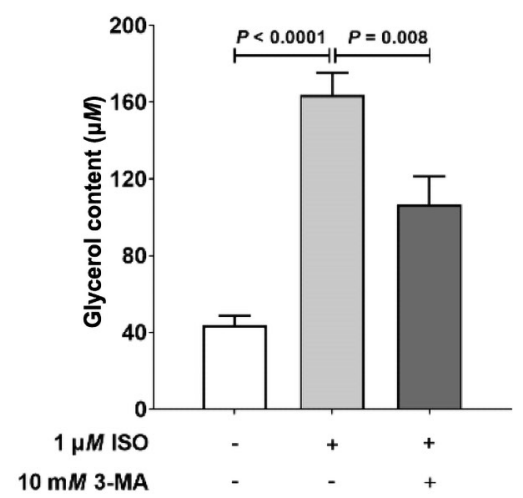

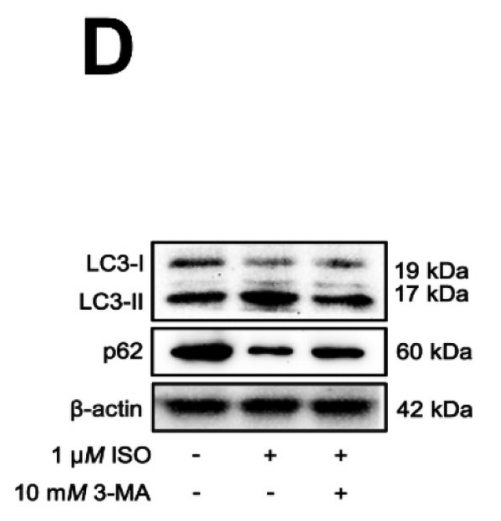

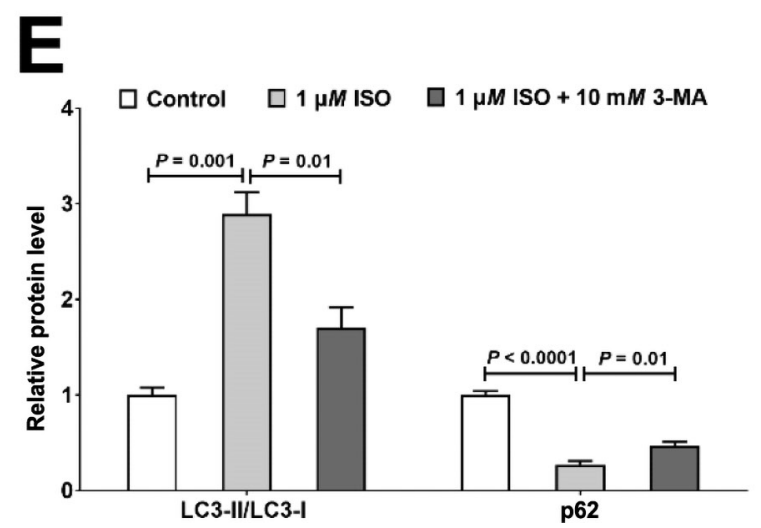

Figure 4. Effect of increased lipolysis on autophagy in calf adipocytes. Panel A shows representative western blotting analysis of lipolysisrelated proteins as indicated by the relative abundance of ATGL and PLIN1 and the ratio of phosphorylated (p)-HSL to HSL (panel B). Panel C shows glycerol content in the supernatant from cultured adipocytes. Panel D shows representative western blotting analysis of autophagy-related proteins as indicated by the ratio of MAP1LC3 (also called LC3-II) to LC3-I and the relative abundance of SQSTM1 (also called p62; panel E). Calf adipocytes were assigned to 3 treatments as follows: (1) control: cells incubated with Dulbecco's modified Eagle medium (DMEM)/ F12 for $24 \mathrm{~h}$; (2) cells incubated with DMEM/F12 for $21 \mathrm{~h}$ followed by treatment with isoproterenol (ISO; $1 \mu M$ ) for an additional 3 h; (3) cells incubated with DMEM/F12 for $20 \mathrm{~h}$ followed by treatment with 3-methyladenine (3-MA; $10 \mathrm{~m} M)$ for $4 \mathrm{~h}$ and ISO $(1 \mu M)$ for $3 \mathrm{~h}$. Results are expressed as means \pm SEM. $P$-values indicate group differences. Cell culture treatment was repeated using 6 calves, respectively.

supply). Cells can reach the same metabolic state after induction of differentiation in vitro, which renders the system more conducive for mechanistic experiments in vitro.

Degradation of LD mediated by autophagy contributes to lipolysis in adipocytes in a process termed lipophagy (Cingolani and Czaja, 2016). Free fatty acids are liberated after lipophagy, which contributes to providing sources of energy via $\beta$-oxidation during starvation (Liu and Czaja, 2013; Kaushik and Cuervo, 2015). For instance, in mouse brown adipose tissue and liver, induction of lipophagy in response to autophagy activation of proopiomelanocortin neurons under cold stimulation led to an increase in fatty acid concentrations (Martinez-Lopez et al., 2016). Earlier studies have proved that TAG storage in LD increased when autophagy was inhibited in mouse liver and cultured hepatocytes (Singh et al., 2009) and caused hepatic steatosis (Liu and Czaja, 2013). Beclin1 is one of the major molecules for nucleation of the phagophore, and studies in mice demonstrate that adipose-specific knockout of Beclin1 impairs lipolysis (Son et al., 2020). MartinezLopez et al. (2016) also reported that LC3 recruited ATGL or HSL at the LD surface through interacting region motifs, and the ATGL-mediated lipolysis could be blocked by LIR motif mutating. Thus, at least in nonruminants, the data demonstrated that autophagy was associated with adipocyte lipolysis.

The compound 3-MA, a pharmacological autophagy inhibitor, can alter the early steps of autophagosome formation (Dai et al., 2013). We found that 3-MA resulted in a pronounced decrease of lipolysis, in part through downregulating the abundance of ATGL, the ratio of p-HSL to HSL, and the glycerol content, 
and upregulating the abundance of PLIN1. It was noteworthy that 3-MA could reverse the effects of ISO on lipolysis. Rapamycin can upregulate the level of autophagy (Yu et al., 2019). Martinez-Lopez et al. (2016) demonstrated that hypothalamic Rapa injection triggered lipid utilization in mice. In our cultured cell study, the increased abundance of ATGL, the ratio of p-HSL to HSL, the glycerol content, and the decreased abundance of PLIN1 in response to Rapa suggested that in vivo changes in autophagic activity during negative nutrient balance could facilitate lipolysis to maintain a constant supply of fatty acids as energy sources. A previous study also reported that lipolysis and autophagy were upregulated during nutrient stress (Rambold et al., 2015).

The coordination of adipose tissue metabolism is crucial for helping cows make uneventful transitions into lactation and maintain the overall efficiency of milk production (Khan et al., 2013). In the present study, we first confirmed a link between elevated lipolysis and enhanced autophagy in adipose tissue of dairy cows with fatty liver in early lactation. Together, our data indicated that enhanced autophagy could promote TAG breakdown in adipocytes of dairy cows. Furthermore, autophagy could act as a potential therapeutic target for prevention and treatment of fatty liver in early lactation, but the specific molecular mechanism needs to be further investigated.

\section{CONCLUSIONS}

Using cow and cell culture studies, we were able to show that lipolysis is associated with autophagy in adipose tissue of high-yielding dairy cows with fatty liver during early lactation. Targeting autophagy could lead to therapeutic applications for manipulating the response of adipose tissue to metabolic stresses in dairy cows during the transition period.

\section{ACKNOWLEDGMENTS}

This work was supported by the National Natural Science Foundation of China (Beijing, China; grant nos. 32022084 and 32172927) and the Fundamental Research Funds for the Central Universities (Beijing, China). The authors have not stated any conflicts of interest.

\section{REFERENCES}

Ailhaud, G. 1982. Adipose cell differentiation in culture. Mol. Cell. Biochem. 49:17-31. https://doi.org/10.1007/BF00230992.

Andres Contreras, G., J. De Koster, J. de Souza, J. Laguna, V. Mavangira, R. K. Nelli, J. Gandy, A. L. Lock, and L. M. Sordillo. 2020. Lipolysis modulates the biosynthesis of inflammatory lipid mediators derived from linoleic acid in adipose tissue of periparturient dairy cows. J. Dairy Sci. 103:1944-1955. https://doi.org/10 $.3168 /$ jds.2019-17256.

Bjørkøy, G., T. Lamark, A. Brech, H. Outzen, M. Perander, A. Overvatn, H. Stenmark, and T. Johansen. 2005. p62/SQSTM1 forms protein aggregates degraded by autophagy and has a protective effect on huntingtin-induced cell death. J. Cell Biol. 171:603-614. https://doi.org/10.1083/jcb.200507002.

Björntorp, P., M. Karlsson, P. Pettersson, and G. Sypniewska. 1980. Differentiation and function of rat adipocyte precursor cells in primary culture. J. Lipid Res. 21:714-723. https://doi.org/10.1016/ S0022-2275(20)34799-4.

Bobe, G., J. W. Young, and D. C. Beitz. 2004. Invited review: Pathology, etiology, prevention, and treatment of fatty liver in dairy cows. J. Dairy Sci. 87:3105-3124. https://doi.org/10.3168/jds .S0022-0302(04)73446-3.

Bolsoni-Lopes, A., and M. I. Alonso-Vale. 2015. Lipolysis and lipases in white adipose tissue - An update. Arch. Endocrinol. Metab. 59:335-342. https://doi.org/10.1590/2359-3997000000067.

Cairó, M., J. Villarroya, R. Cereijo, L. Campderros, M. Giralt, and F. Villarroya. 2016. Thermogenic activation represses autophagy in brown adipose tissue. Int. J. Obes. (Lond.) 40:1591-1599. https:// doi.org/10.1038/ijo.2016.115

Chakrabarti, P., J. Y. Kim, M. Singh, Y. K. Shin, J. Kim, J. Kumbrink, Y. Wu, M. J. Lee, K. H. Kirsch, S. K. Fried, and K. V. Kandror. 2013. Insulin inhibits lipolysis in adipocytes via the evolutionarily conserved mTORC1-Egr1-ATGL-mediated pathway. Mol. Cell. Biol. 33:3659-3666. https://doi.org/10.1128/MCB.01584-12.

Chen, M., J. J. Loor, Q. Zhai, Y. Liang, H. Yu, X. Du, T. Shen, Z. Fang, Z. Shi, X. Wang, Y. Zhu, Y. Song, G. Liu, X. Li, Z. Wang, and X. Li. 2020. Short communication: Enhanced autophagy activity in liver tissue of dairy cows with mild fatty liver. J. Dairy Sci. 103:3628-3635. https://doi.org/10.3168/jds.2019-17457.

Chitraju, C., N. Mejhert, J. T. Haas, L. G. Diaz-Ramirez, C. A. Grueter, J. E. Imbriglio, S. Pinto, S. K. Koliwad, T. C. Walther, and R. V. Farese Jr.. 2017. Triglyceride synthesis by DGAT1 protects adipocytes from lipid-induced ER stress during lipolysis. Cell Metab. 26:407-418.e3. https://doi.org/10.1016/j.cmet.2017.07.012.

Cingolani, F., and M. J. Czaja. 2016. Regulation and functions of autophagic lipolysis. Trends Endocrinol. Metab. 27:696-705. https:/ /doi.org/10.1016/j.tem.2016.06.003.

Dai, X. Y., M. M. Zhao, Y. Cai, Q. C. Guan, Y. Zhao, Y. F. Guan, W. Kong, W. G. Zhu, M. J. Xu, and X. Wang. 2013. Phosphateinduced autophagy counteracts vascular calcification by reducing matrix vesicle release. Kidney Int. 83:1042-1051. https://doi.org/ 10.1038/ki.2012.482.

Dong, J. 2021. Increased adipose tissue lipolysis in dairy cows with fatty liver is associated with enhanced autophagy activity. Mendeley Data, V1. https://doi.org/10.17632/nnh2gkg8nv.1.

Dong, J., G. Bobe, Y. Guan, G. J. Li, R. Zuo, X. Shu, Y. Wang, X. D. Sun, X. Y. Chen, and X. W. Li. 2020. Mitochondrial membrane protein mitofusin 2 as a potential therapeutic target for treating free fatty acid-induced hepatic inflammation in dairy cows during early lactation. J. Dairy Sci. 103:5561-5574. https://doi.org/ 10.3168/jds.2019-17652.

Du, X., G. Liu, J. J. Loor, Z. Fang, R. Bucktrout, Y. Yang, Q. Ye, Z. Shi, T. Shen, X. Wang, Z. Peng, C. Zhao, B. Lv, D. Xing, Y. Zhu, X. Li, and X. Li. 2018. Impaired hepatic autophagic activity in dairy cows with severe fatty liver is associated with inflammation and reduced liver function. J. Dairy Sci. 101:11175-11185. https:/ /doi.org/10.3168/jds.2018-15120.

Du, X., Z. Shi, Z. Peng, C. Zhao, Y. Zhang, Z. Wang, X. Li, G. Liu, and X. Li. 2017. Acetoacetate induces hepatocytes apoptosis by the ROS-mediated MAPKs pathway in ketotic cows. J. Cell. Physiol. 232:3296-3308. https://doi.org/10.1002/jcp.25773.

Edmonson, A. J., I. J. Lean, L. D. Weaver, T. Farver, and G. Webster. 1989. A body condition scoring chart for Holstein dairy cows. J. Dairy Sci. 72:68-78. https://doi.org/10.3168/jds.S0022 $-0302(89) 79081-0$.

Farke, C., H. H. Meyer, R. M. Bruckmaier, and C. Albrecht. 2008. Differential expression of $\mathrm{ABC}$ transporters and their regula- 
tory genes during lactation and dry period in bovine mammary tissue. J. Dairy Res. 75:406-414. https://doi.org/10.1017/ S002202990800335X.

Glick, D., S. Barth, and K. F. Macleod. 2010. Autophagy: Cellular and molecular mechanisms. J. Pathol. 221:3-12. https://doi.org/ 10.1002/path.2697.

Grummer, R. R. 1993. Etiology of lipid-related metabolic disorders in periparturient dairy cows. J. Dairy Sci. 76:3882-3896. https://doi .org/10.3168/jds.S0022-0302(93)77729-2.

He, C., and D. J. Klionsky. 2009. Regulation mechanisms and signaling pathways of autophagy. Annu. Rev. Genet. 43:67-93. https://doi .org/10.1146/annurev-genet-102808-114910.

IACUC. 2018. Sample Size Calculations (IACUC). Accessed May 1, 2018. https://www.bu.edu/researchsupport/compliance/animal -care/working-with-animals/research/sample-size-calculations -iacuc/.

Ichimura, Y., T. Kumanomidou, Y. S. Sou, T. Mizushima, J. Ezaki, T. Ueno, E. Kominami, T. Yamane, K. Tanaka, and M. Komatsu. 2008. Structural basis for sorting mechanism of p62 in selective autophagy. J. Biol. Chem. 283:22847-22857. https://doi.org/10 .1074/jbc.M802182200.

Jang, Y. H., K. Y. Choi, and D. S. Min. 2014. Phospholipase Dmediated autophagic regulation is a potential target for cancer therapy. Cell Death Differ. 21:533-546. https://doi.org/10.1038/ cdd.2013.174.

Jia, H., X. Li, G. Liu, J. J. Loor, R. Bucktrout, X. Sun, G. Li, X. Shu, J. Dong, Y. Wang, R. Zuo, Z. Wang, and X. Li. 2019. Perilipin 5 promotes hepatic steatosis in dairy cows through increasing lipid synthesis and decreasing very-low-density lipoprotein assembly. J. Dairy Sci. 102:833-845. https://doi.org/10.3168/jds.2018-15208.

Kabeya, Y., N. Mizushima, T. Ueno, A. Yamamoto, T. Kirisako, T. Noda, E. Kominami, Y. Ohsumi, and T. Yoshimori. 2000. LC3, a mammalian homologue of yeast Apg8p, is localized in autophagosome membranes after processing. EMBO J. 19:5720-5728. https: //doi.org/10.1093/emboj/19.21.5720.

Kaushik, S., and A. M. Cuervo. 2015. Degradation of lipid dropletassociated proteins by chaperone-mediated autophagy facilitates lipolysis. Nat. Cell Biol. 17:759-770. https://doi.org/10.1038/ ncb3166.

Khan, M. J., A. Hosseini, S. Burrell, S. M. Rocco, J. P. McNamara, and J. J. Loor. 2013. Change in subcutaneous adipose tissue metabolism and gene network expression during the transition period in dairy cows, including differences due to sire genetic merit. J. Dairy Sci. 96:2171-2182. https://doi.org/10.3168/jds.2012-5794.

Kim, J., M. Kundu, B. Viollet, and K. L. Guan. 2011. AMPK and mTOR regulate autophagy through direct phosphorylation of Ulk1. Nat. Cell Biol. 13:132-141. https://doi.org/10.1038/ncb2152.

Klein, S. L., C. Scheper, K. Brugemann, H. H. Swalve, and S. Konig. 2019. Phenotypic relationships, genetic parameters, genome-wide associations, and identification of potential candidate genes for ketosis and fat-to-protein ratio in German Holstein cows. J. Dairy Sci. 102:6276-6287. https://doi.org/10.3168/jds.2019-16237.

Li, X., G. Li, X. Du, X. Sun, Z. Peng, C. Zhao, Q. Xu, A. M. Abdelatty, F. F. Mohamed, Z. Wang, and G. Liu. 2020. Increased autophagy mediates the adaptive mechanism of the mammary gland in dairy cows with hyperketonemia. J. Dairy Sci. 103:2545-2555. https://doi.org/10.3168/jds.2019-16910.

Liu, K., and M. J. Czaja. 2013. Regulation of lipid stores and metabolism by lipophagy. Cell Death Differ. 20:3-11. https://doi.org/10 $.1038 /$ cdd.2012.63.

Liu, L., X. Li, Y. Li, Y. Guan, Y. Song, L. Yin, H. Chen, L. Lei, J. Liu, X. Li, Z. Wang, X. Yang, and G. Liu. 2014. Effects of nonesterified fatty acids on the synthesis and assembly of very low density lipoprotein in bovine hepatocytes in vitro. J. Dairy Sci. 97:1328-1335. https://doi.org/10.3168/jds.2013-6654.

Loor, J. J. 2010. Genomics of metabolic adaptations in the peripartal cow. Animal 4:1110-1139. https://doi.org/10.1017/ S1751731110000960.

Malafaia, P., Y. T. G. Salcedo, R. A. R. Uscategui, V. C. Souza, D. F. A. Costa, and T. T. Berchielli. 2017. A simple and fast sampling method for chemical analyses and densitometry of bones through rib biopsies in cattle. Pesqui. Vet. Bras. 37:31-35. https://doi.org/ 10.1590/s0100-736x2017000100005.

Martinez-Lopez, N., M. Garcia-Macia, S. Sahu, D. Athonvarangkul, E. Liebling, P. Merlo, F. Cecconi, G. J. Schwartz, and R. Singh. 2016. Autophagy in the CNS and periphery coordinate lipophagy and lipolysis in the brown adipose tissue and liver. Cell Metab. 23:113-127. https://doi.org/10.1016/j.cmet.2015.10.008.

Noda, N. N., Y. Fujioka, T. Hanada, Y. Ohsumi, and F. Inagaki. 2013. Structure of the Atg12-Atg5 conjugate reveals a platform for stimulating Atg8-PE conjugation. EMBO Rep. 14:206-211. https: //doi.org/10.1038/embor.2012.208.

Ospina, P. A., J. A. Mcart, T. R. Overton, T. Stokol, and D. V. Nydam. 2013. Using nonesterified fatty acids and beta-hydroxybutyrate concentrations during the transition period for herd-level monitoring of increased risk of disease and decreased reproductive and milking performance. Vet. Clin. North Am. Food Anim. Pract. 29:387-412. https://doi.org/10.1016/j.cvfa.2013.04.003.

Park, J. R., J. W. Jung, M. S. Seo, S. K. Kang, Y. S. Lee, and K. S. Kang. 2010. DNER modulates adipogenesis of human adipose tissue-derived mesenchymal stem cells via regulation of cell proliferation. Cell Prolif. 43:19-28. https://doi.org/10.1111/j.1365-2184 2009.00650.x.

Rambold, A. S., S. Cohen, and J. Lippincott-Schwartz. 2015. Fatty acid trafficking in starved cells: regulation by lipid droplet lipolysis, autophagy, and mitochondrial fusion dynamics. Dev. Cell 32:678-692. https://doi.org/10.1016/j.devcel.2015.01.029.

Reid, I. M. 1980. Incidence and severity of fatty liver in dairy cows. Vet. Rec. 107:281-284. https://doi.org/10.1136/vr.107.12.281.

Schweiger, M., R. Schreiber, G. Haemmerle, A. Lass, C. Fledelius, P. Jacobsen, H. Tornqvist, R. Zechner, and R. Zimmermann. 2006. Adipose triglyceride lipase and hormone-sensitive lipase are the major enzymes in adipose tissue triacylglycerol catabolism. J. Biol. Chem. 281:40236-40241. https://doi.org/10.1074/jbc .M608048200.

Singh, R., S. Kaushik, Y. J. Wang, Y. Q. Xiang, I. Novak, M. Komatsu, K. Tanaka, A. M. Cuervo, and M. J. Czaja. 2009. Autophagy regulates lipid metabolism. Nature 458:1131-1135. https://doi .org/10.1038/nature07976.

Son, Y., Y. K. Cho, A. Saha, H. J. Kwon, J. H. Park, M. Kim, Y. S. Jung, S. N. Kim, C. Choi, J. K. Seong, R. B. Burl, J. G. Granneman, and Y. H. Lee. 2020. Adipocyte-specific Beclin1 deletion impairs lipolysis and mitochondrial integrity in adipose tissue. Mol. Metab. 39:101005. https://doi.org/10.1016/j.molmet .2020 .101005 .

Sun, X., X. Li, H. Jia, J. J. Loor, R. Bucktrout, Q. Xu, Y. Wang, X. Shu, J. Dong, R. Zuo, L. Yang, G. Liu, and X. Li. 2019. Effect of heat-shock protein B7 on oxidative stress in adipocytes from preruminant calves. J. Dairy Sci. 102:5673-5685. https://doi.org/ 10.3168/jds.2018-15726.

Tao, Z., L. Liu, L. D. Zheng, and Z. Cheng. 2019. Autophagy in adipocyte differentiation. Methods Mol. Biol. 1854:45-53. https://doi .org/10.1007/7651_2017_65.

Wang, H., M. Bell, U. Sreenevasan, H. Hu, J. Liu, K. Dalen, C. Londos, T. Yamaguchi, M. A. Rizzo, R. Coleman, D. Gong, D. Brasaemle, and C. Sztalryd. 2011. Unique regulation of adipose triglyceride lipase (ATGL) by perilipin 5, a lipid droplet-associated protein. J. Biol. Chem. 286:15707-15715. https://doi.org/10.1074/ jbc.M110.207779.

Wang, X., R. Wu, Y. Liu, Y. Zhao, Z. Bi, Y. Yao, Q. Liu, H. Shi, F. Wang, and Y. Wang. 2020. m(6)A mRNA methylation controls autophagy and adipogenesis by targeting Atg5 and Atg7. Autophagy 16:1221-1235. https://doi.org/10.1080/15548627.2019.1659617.

Wensing, T., T. Kruip, M. Geelen, G. H. Wentink, and A. M. van den Top. 1997. Postpartum fatty liver in high-producing dairy cows in practice and in animal studies. The connection with health, production and reproduction problems. Comp. Haematol. Int. 7:167-171. https://doi.org/10.1007/BF02652596.

Xu, Q., H. Jia, L. Ma, G. Liu, C. Xu, Y. Li, X. Li, and X. Li. 2019b. All-trans retinoic acid inhibits lipopolysaccharide-induced inflammatory responses in bovine adipocytes via TGF beta $1 / \mathrm{Smad} 3$ 
signaling pathway. BMC Vet. Res. 15:48. https://doi.org/10.1186/ s12917-019-1791-2.

Xu, Q., X. Li, L. Ma, J. J. Loor, D. N. Coleman, H. Jia, G. Liu, C. Xu, Y. Wang, and X. Li. 2019a. Adipose tissue proteomic analysis in ketotic or healthy Holstein cows in early lactation1. J. Anim. Sci. 97:2837-2849. https://doi.org/10.1093/jas/skz132.

Yu, M., C. C. Luo, X. Huang, D. Y. Chen, S. S. Li, H. Qi, and X. J. Gao. 2019. Amino acids stimulate glycyl-tRNA synthetase nuclear localization for mammalian target of rapamycin expression in bovine mammary epithelial cells. J. Cell. Physiol. 234:7608-7621. https://doi.org/10.1002/jcp.27523.

Zachut, M., G. Kra, L. Livshitz, Y. Portnick, S. Yakoby, G. Friedlander, and Y. Levin. 2017. Seasonal heat stress affects adipose tissue proteome toward enrichment of the Nrf2-mediated oxidative stress response in late-pregnant dairy cows. J. Proteomics 158:52-61. https://doi.org/10.1016/j.jprot.2017.02.011.

Zhang, S., G. Liu, C. Xu, L. Liu, Q. Zhang, Q. Xu, H. Jia, X. Li, and X. Li. 2018. Perilipin 1 mediates lipid metabolism homeostasis and inhibits inflammatory cytokine synthesis in bovine adipocytes. Front. Immunol. 9:467. https://doi.org/10.3389/fimmu.2018 .00467 .

Zhang, X., D. Wu, C. Wang, Y. Luo, X. Ding, X. Yang, F. Silva, S. Arenas, J. M. Weaver, M. Mandell, V. Deretic, and M. Liu. 2020.
Sustained activation of autophagy suppresses adipocyte maturation via a lipolysis-dependent mechanism. Autophagy 16:16681682. https://doi.org/10.1080/15548627.2019.1703355.

Zhang, Y., X. Zeng, and S. Jin. 2012. Autophagy in adipose tissue biology. Pharmacol. Res. 66:505-512. https://doi.org/10.1016/j.phrs 2012.09.004.

Zhu, Y., Y. Guan, J. J. Loor, X. Sha, D. N. Coleman, C. Zhang, X. Du, Z. Shi, X. Li, Z. Wang, G. Liu, and X. Li. 2019. Fatty acidinduced endoplasmic reticulum stress promoted lipid accumulation in calf hepatocytes, and endoplasmic reticulum stress existed in the liver of severe fatty liver cows. J. Dairy Sci. 102:7359-7370. https://doi.org/10.3168/jds.2018-16015.

\section{ORCIDS}

Juan J. Loor @ https://orcid.org/0000-0003-1586-4365 Ahmad Aboragah @ https://orcid.org/0000-0003-4340-0066 Xiliang Du (ㄱ https://orcid.org/0000-0002-1467-6998 Guowen Liu @

Xiaobing Li ๑ https://orcid.org/0000-0001-9105-6365

Xinwei Li ๑ https://orcid.org/0000-0002-0765-677X 